\title{
Rigid bronchoscopy in malignant airway fistula using dexmedetomidine
}

\author{
Benedikt Kowalski ${ }^{1}$, Hülya Begdeda ${ }^{2}$, Bastian Grande ${ }^{2}$, Claudio Caviezel ${ }^{3}$, Marco P. Zalunardo $^{2}$, \\ Daniel P. Franzen ${ }^{1}$
}

${ }^{1}$ Department of Pulmonology, University Hospital Zurich, Zurich, Switzerland; ${ }^{2}$ Institute of Anesthesiology, University Hospital Zurich, Zurich, Switzerland; ${ }^{3}$ Department of Thoracic Surgery, University Hospital Zurich, Zurich, Switzerland

Correspondence to: Dr. Daniel P. Franzen, MD, FCCP. Department of Pulmonology, University Hospital Zurich, Rämistr. 100, 8091 Zurich, Switzerland. Email: daniel.franzen@usz.ch.

Submitted Apr 29, 2020. Accepted for publication Aug 26, 2020.

doi: $10.21037 /$ jtd-20-1780

View this article at: http://dx.doi.org/10.21037/jtd-20-1780

\section{Introduction}

Esophageal and tracheal stenting is an effective palliative treatment of malignant tracheo-esophageal (TEF) and trachea-mediastinal fistula (TMF) to relieve dyspnea and dysphagia (1), and to improve quality of life (2). Rigid bronchoscopy (RB) is commonly used to place tracheal stents to seal the lesion from the airway side (3). However, general anesthesia and jet ventilation required for $\mathrm{RB}$ may cause gastric distension, pneumomediastinum or worsening of the fistula (4). Thus, a safe sedation technique enabling $\mathrm{RB}$ in spontaneous respiration might be promising.

Dexmedetomidine is an $\alpha_{2}$ receptor agonist with sympatholytic and sedative characteristics, which has been shown to enable moderate sedation for several procedures including airway foreign body removal through $\mathrm{RB}$ in pediatric patients (5). Apart from one publication (6), to our knowledge there are no reports on tracheal stenting through RB using dexmedetomidine.

Here, we present three cases with successful tracheal stent placement through $\mathrm{RB}$ in moderate sedation and spontaneous respiration using dexmedetomidine to seal TEF or TMF. All patients gave the consent to this technique and a general consent to present the data.

\section{Case presentation}

\section{Case 1}

A 57-year-old male with squamous cell carcinoma (cT4cN2cM0, UICC IIIB) in the posterior mediastinum presented with an esophageal stent penetrating into the trachea, subsequently causing a $95 \%$ stenosis in the lower trachea (Figure 1A). Successful placement of a 18-14$14 \mathrm{~mm}$ fully covered aerstent ${ }^{\circledR} \mathrm{Y}$ Carina-Stent (Leufen, Medical GmbH, bess AG, Berlin, Germany) through a $12 \mathrm{~mm}$ Storz rigid tracheoscope (Karl Storz SE \& Co. KG, Tuttlingen, Germany) was performed to seal the leakage using fluoroscopy (Figure 1B). Anesthesia was provided using a continuous infusion pump with remifentantil (TCI $0.5-1 \mathrm{mcg} / \mathrm{mL}$ ) and dexmedetomidine. For the latter, a dosage of $4 \mu \mathrm{g} / \mathrm{kg} / \mathrm{h}$ over 15 minutes or until Richmond Agitation Sedation Scale (RASS) reached -1 or -2 , followed by reduction to 0.7 to $1 \mu \mathrm{g} / \mathrm{kg} / \mathrm{h}$ until approximately 10 minutes before end of procedure. In addition, a few propofol boli were added (Table 1). The patient tolerated the procedure without negative recalls, was arousable and breathing spontaneously throughout the entire intervention. The postinterventional follow-up was uneventful, and the patient was able to maintain a satisfactory life without dyspnea for 12 months thereafter.

\section{Case 2}

A 68-year-old male patient with relapsing small cell lung carcinoma (cT3cN2M0) presented with a $30 \mathrm{~mm}$ TMF in the anterior trachea and aspiration pneumonia. TMF was sealed using oxidized regenerated cellulose (Tabotamp $^{\circledR}$, Ethicon Inc., Somerville, NJ, USA) and fibrin sealant (Tisseel ${ }^{\circledR}$, Baxter AG, Opfikon, Switzerland) (Figure 2A,B). Thereafter, an 18-14-14 mm fully covered 

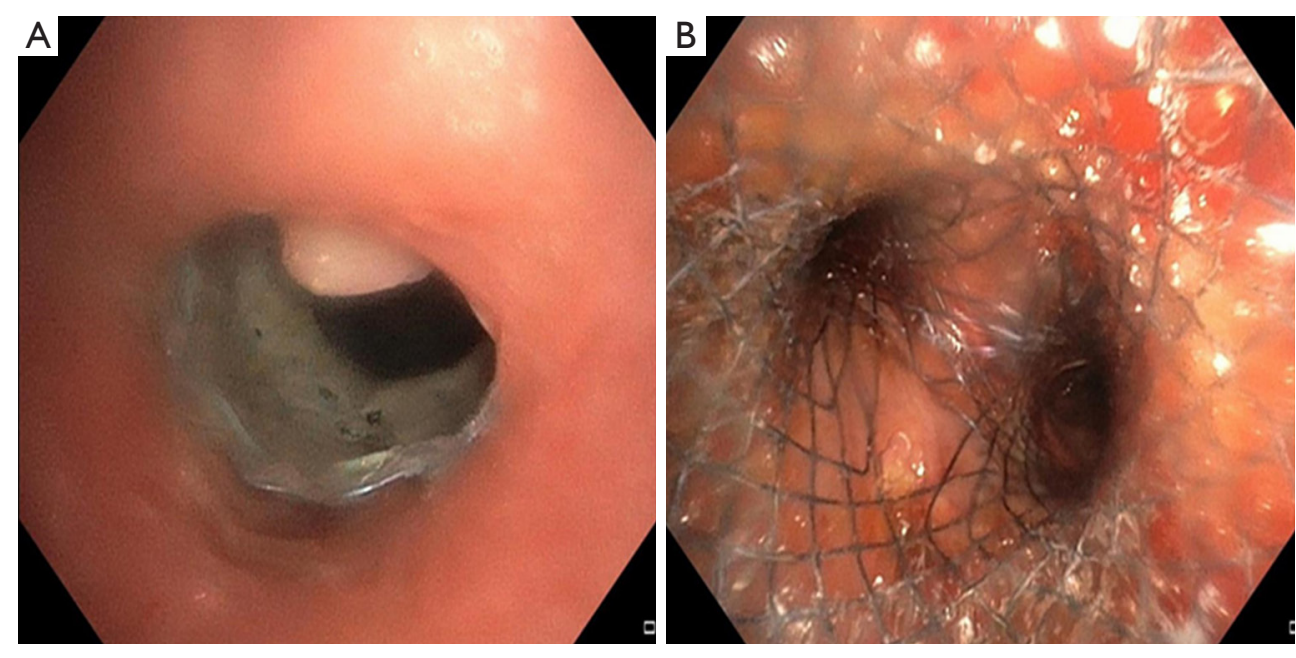

Figure 1 Rigid bronchoscopy of case 1. (A) Upper tracheal view with penetrated esophagus stent causing a 95\% stenosis; (B) lower tracheal view after stenting using an aerstent ${ }^{\circledR} \mathrm{Y}$ Carina-Stent (Leufen, Medical GmbH, bess AG, Berlin, Germany).

Table 1 Cumulative doses of sedative and analgetic medications for rigid bronchoscopy in spontaneous ventilation

\begin{tabular}{lccc}
\hline & Case 1 & Case 2 & Case 3 \\
\hline Propofol $(\mathrm{mg})$ & 80 & - & 120 \\
Remifentanil $(\mu \mathrm{g})$ & 540 & 410 & 490 \\
Dexmedetomidine $(\mu \mathrm{g})$ & 105 & 150 & 160 \\
\hline
\end{tabular}

aerstent ${ }^{\circledast} \mathrm{Y}$ Carina-Stent was placed through a $12 \mathrm{~mm}$ rigid tracheoscope using fluoroscopy (Figure 2C). Anesthesia was provided using the identical drug and dose regimen as in case 1 (Table 1). The patient remained awake, yet stable and free of dyspnea and pain throughout the whole intervention. The post-interventional follow-up was uneventful. The patient's main symptoms, dyspnea and dysphagia, were relieved. However, the patient died two weeks later of disease progression.

\section{Case 3}

A 72-year-old male with relapsing squamous cell carcinoma of the proximal esophagus ( $\mathrm{cT} 3 \mathrm{cN} 1 \mathrm{M} 0)$ presented with an esophageal stent perforating the trachea about $3 \mathrm{~cm}$ below the vocal cords and causing $60 \%$ tracheal stenosis and complete obstruction of the left main bronchus (Figure $3 A$ ). Placement of a 16-12-12 mm aerstent ${ }^{\circledR}$ $Y$ Carina Stent with the proximal end right below the cranial fistula orifice (Figure $3 B$ ) and stent extension using a partially covered, straight $16 \times 40 \mathrm{~mm}$ Ultraflex $^{\mathrm{TM}}$ Stent (Figure 3C) (BostonScientific, Marlborough, MA, USA) using a $14 \mathrm{~mm}$ rigid tracheoscope and fluoroscopy succeeded by administering several propofol boli, remifentanil and continuous infusion of dexmedetomidine (Table 1). A small gap between stent and trachea wall remained at the end (Figure 3D), and the esophagus stent was left unchanged. Anesthesia was again provided using a similar drug and dose regimen as in case 1 . However, the tapering dose of dexmedetomidine ranged between $1-2.1 \mu \mathrm{g} / \mathrm{kg} / \mathrm{h}$ until approximately 10 minutes before end of procedure. The interventions were tolerated without further distress or complications and relieved the patient effectively of his symptoms, most of all dyspnea and dysphagia. Seven days later he died of disease progression.

\section{Discussion}

The general condition of patients with TEF/TMF is generally poor due to recurrent aspiration pneumonia and the underlying cancer itself. Additionally, life expectancy precludes major surgery. Endoscopic stenting is the treatment of choice in the majority of cases (1). Eventually immediate closure of the lesion is of highest priority to prevent repeated aspiration. It is recommended to close the esophageal fistula orifice using coated self-expanding metallic stents as initial step (1). For isolated esophageal stenting procedures, analgosedation using combined administration of propofol and opiates seems adequate. 

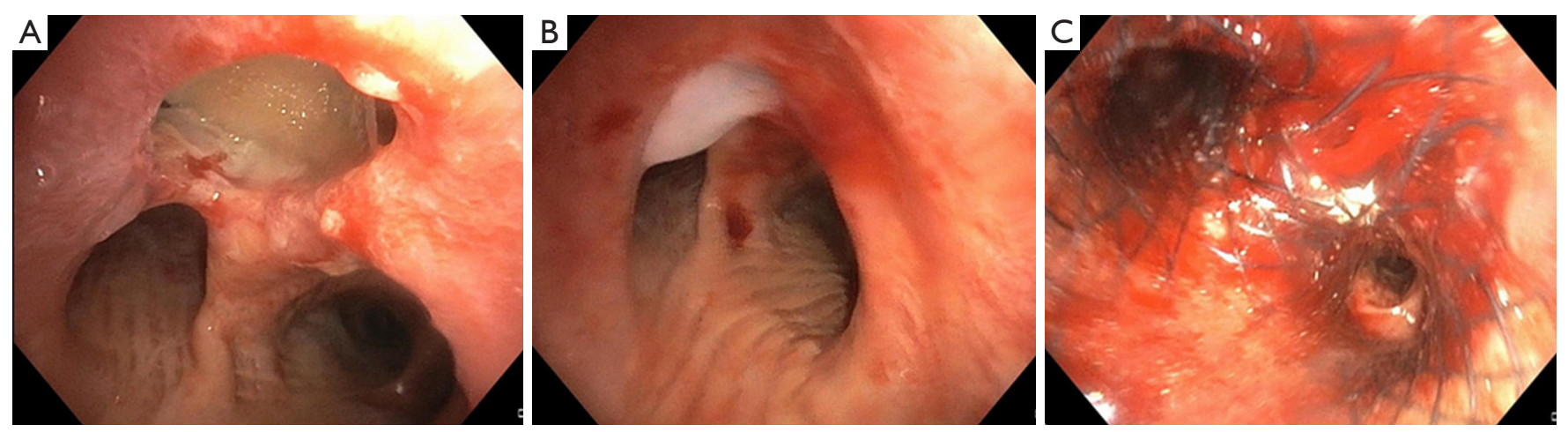

Figure 2 Rigid bronchoscopy of case 2. (A) lower tracheal view revealing a large, supracarinal TMF; (B) lower tracheal view, TMF covered with fibrin sealant; (C) lower tracheal view after stenting using an aerstent ${ }^{\circledR}$ Y Carina-Stent (Leufen, Medical GmbH, bess AG, Berlin, Germany).
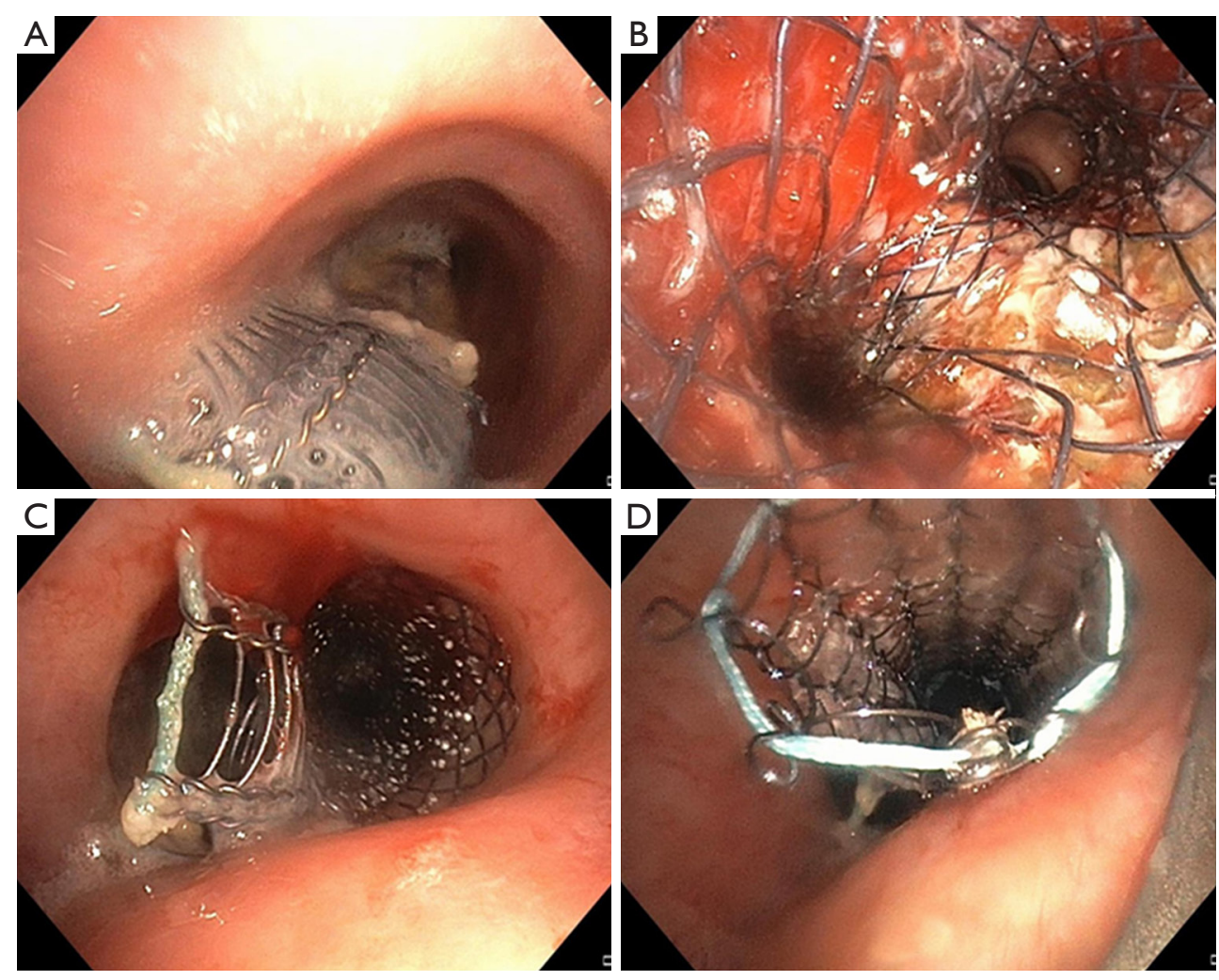

Figure 3 Rigid bronchoscopy of case 3. (A) upper tracheal view with esophageal stent perforating the trachea; (B) lower tracheal view after stenting using an aerstent ${ }^{\circledR}$ Y Carina-Stent (Leufen, Medical GmbH, bess AG, Berlin, Germany); (C) upper tracheal view with persistent TEF above Y stent; (D) showing proximal stent extension using a partially covered, straight $16 \times 40 \mathrm{~mm}^{\text {Ultraflex }}{ }^{\mathrm{TM}}$ Stent $($ BostonScientific, Marlborough, MA, USA).

However, in case of secondary tracheal compression with symptomatic central airway stenosis or penetration of the esophageal stent into the tracheobronchial system (as shown in case 1 and 3), or in case of TMF (case 2), tracheo- (bronchial) stenting is the treatment option of choice. In this case, the anesthesiological and airway management becomes more complex. Basically, it is feasible to insert bronchial self-expandable stents using flexible bronchoscopy 
in mild sedation only (7). However, TEF/TMF often require insertion of a $\mathrm{Y}$ or straight tracheal stent. Rigid bronchoscopy provides ideal prerequisites for safe gas exchange in combination with an adequate working channel for several procedures. To date, tracheal stenting using rigid bronchoscopy unconditionally requires general anesthesia and positive pressure or jet ventilation (1). The latter might need to advance the bronchoscope distally to the fistula, which impedes visualization and intervention. Therefore, the traditional technique requires apnea periods without any ventilation, which further stresses gas exchange and the very limited time to complete stent placement. Eventually, intraoperative fatal outcomes are not uncommon (8). A very recent study by Murgu et al. suggests that RB can be safely performed with total intravenous anesthesia and spontaneous ventilation (9). However, in their study dexmedetomidine was only used in two patients without evidence of the procedure details. Our three patients with severe TEF or TMF tolerated RB using dexmedetomidine without pain or stress after careful local anesthesia using lidocaine $10 \%$ spray. During potentially painful or stressful periods, its effect was supplemented with remifentanil and propofol. In addition, dexmedetomidine has been used in combination with small bolus' of propofol (10-20 mg) to suppress coughing and for a safe insertion of the rigid bronchoscope according to Kim et al. (10). The sedation has been estimated by clinical assessment and the RASS (Richmond Agitation and Sedation Scale) with the aim of -1 to -2 . Spontaneous breathing with sufficient (pre-) oxygenation was maintained at all time in each patient using a face mask and through the bronchoscope, respectively. Meanwhile, the patients were monitored with non-invasive oxygen saturation, ECG, and arterial line to measure blood pressure and arterial $\mathrm{O} 2$ and $\mathrm{CO} 2$.

Eventually, a consented back-up plan in case of underor oversedation must be considered before starting the procedure (i.e., return to traditional technique with general anesthesia and jet ventilation). Relevant prerequisites for this technique is ensuring that anatomy allows for intubation with a rigid bronchoscopy (oral opening, reclination) and a trustful patient-doctor relationship. Furthermore, the patient must be informed that he will not be able to speak during the procedure. Thus, a clear hand signaling must be arranged.

In conclusion, the use of dexmedetomidine was of great benefit for the patients and confirmed the results of previous studies regarding spontaneous respiration and moderate sedation. Based on our experience, using dexmedetomidine spontaneous respiration can be safely maintained even during $\mathrm{RB}$ for interventional repair of TEF/TMF.

\section{Acknowledgments}

Funding: None.

\section{Footnote}

Provenance and Peer Review: This article was a free submission to the journal. The article was sent for external peer review.

Peer Review File: Available at http://dx.doi.org/10.21037/jtd20-1780

Conflicts of Interest: All authors have completed the ICMJE uniform disclosure form (available at http://dx.doi. org/10.21037/jtd-20-1780). The authors have no conflicts of interest to declare.

Ethical Statement: The authors are accountable for all aspects of the work in ensuring that questions related to the accuracy or integrity of any part of the work are appropriately investigated and resolved. All participants gave informed consent before taking part of this case series.

Open Access Statement: This is an Open Access article distributed in accordance with the Creative Commons Attribution-NonCommercial-NoDerivs 4.0 International License (CC BY-NC-ND 4.0), which permits the noncommercial replication and distribution of the article with the strict proviso that no changes or edits are made and the original work is properly cited (including links to both the formal publication through the relevant DOI and the license). See: https://creativecommons.org/licenses/by-nc-nd/4.0/.

\section{References}

1. Bi Y, Ren J, Chen H, et al. Combined airway and esophageal stents implantation for malignant tracheobronchial and esophageal disease: A STROBEcompliant article. Medicine (Baltimore) 2019;98:e14169.

2. Herth FJ, Peter S, Baty F, et al. Combined airway and oesophageal stenting in malignant airway-oesophageal fistulas: a prospective study. Eur Respir J 2010;36:1370-4.

3. Hurtgen M, Herber SCA. Treatment of malignant tracheoesophageal fistula. Thorac Surg Clin 
2014;24:117-27.

4. Shamji FM, Inculet R. Management of malignant tracheoesophageal fistula. Thorac Surg Clin 2018;28:393-402.

5. Rubinstein-Agunin P, Leiro-Riera R. Dexmedetomidine and bronchoscopy. Int J Clin Anesthesiol 2017;5:1081.

6. Mieda H, Nagano Y, Iwasaki E, et al. Two cases of airway stent placement to treat tracheal and bronchial fistula using general anesthesia under spontaneous respiration. Masui 2012;61:880-4.

7. McGrath EE, Warriner D, Anderson P. The insertion of self expanding metal stents with flexible bronchoscopy under sedation for malignant tracheobronchial stenosis: a single-center retrospective analysis. Arch Bronconeumol

Cite this article as: Kowalski B, Begdeda H, Grande B, Caviezel C, Zalunardo MP, Franzen DP. Rigid bronchoscopy in malignant airway fistula using dexmedetomidine. J Thorac Dis 2020;12(10):6120-6124. doi: 10.21037/jtd-20-1780
2012;48:43-8.

8. Sarper A, Oz N, Cihangir C, et al. The efficacy of selfexpanding metal stents for palliation of malignant esophageal strictures and fistulas. Eur J Cardiothorac Surg 2003;23:794-798.

9. Murgu S, Laxmanan B, Stoy S, et al. Evaluation of safety and short-term outcomes of therapeutic rigid bronchoscopy using total intravenous anesthesia and spontaneous assisted ventilation. Respiration 2020;99:239-247.

10. Kim JY, Lee SY, Kim DH, et al. Effect-site concentration of propofol for reduction of remifentanil-induced cough. Anaesthesia 2010;65:697-703. 